Case Report

\title{
The Role of mPOS System in Process Change and Strategy Change: A Situated Change Perspective
}

\author{
Yao Chin Lin, Nhu-Hang Ha and Kuo-Sung Lin * \\ Department of Information Management, Yuan Ze University, Taoyuan 320, Taiwan; \\ E-Mails: imyclin@saturn.yzu.edu.tw (Y.C.L.); s999212yzu@gmail.com (N.H.H.) \\ * Author to whom correspondence should be addressed; E-Mail: yzu1019202@gmail.com; \\ Tel.: +886-928-464-328.
}

Academic Editor: John J. Regazzi

Received: 30 June 2015 / Accepted: 23 September 2015 / Published: 7 October 2015

\begin{abstract}
The purpose of this study is to revisit the relationship among information technology (IT), Process, and Strategy. We focus on the impact of mobile Point of Sales (mPOS) on changing of operational processes in the restaurant industry. This study investigates the changing of IT strategy and service strategy. The research model was developed based on the literature (strategic alignment model and situated change perspective) and inputs from the restaurant industry and IT experts. The data of this study are collected from observation and face-to-face interviews with both business and IT personnel from 10 restaurants in Taiwan. The findings of this study provide a comprehensive view about the ways processes change once restaurants implements mPOS. We also figure out the impact of this change on IT strategy and service strategy. This study's results shed new light on IT implementation. Researchers need to look at IT in different ways and suggest suitable solutions for practitioners.
\end{abstract}

Keywords: mPOS system; process change; strategy change; organizational change; situated change perspective; restaurant industry

\section{Introduction}

As lifestyles change, dining out becomes more common for consumers who seek new feelings, comfortable environments and happy memories [1]. According to the "2011 Food and Beverage 
(F\&B) for Out-Eaters in Taiwan" survey conducted by Unilever for people eating out, in terms of weekdays, people eat out for lunch 4.2 times on average, dinner 3.3 times, and these numbers are still climbing. As shown in the report, the dine-out budget of Taiwanese people takes up one-third of their annual income. For years, customers have regarded a restaurant's functional attributes - service quality and taste of food - as the most important factors when deciding where to eat. This is still true, however this study also found a shift toward more sophisticated criteria. Intangible, emotional factors are beginning to drive the eating out decisions of customers [2].

Through qualitative interviews, Kim, et al. (2009) found a number of different themes that arose as to why people made the choice to eat out [3], such as exciting experience, escape from routine, togetherness, and convenience. This means that restaurants should change, and this change is far from an easy task for restaurants [2]. Thus, several restaurants are looking for information technology (IT) to support their organizational change [4]. POS (point-of-sale) is one IT solution that has commonly been used to help run restaurant businesses.

POS, defined as the cashier and server terminals, are equipped with powerful functions and have revolutionized the restaurant industry, which go a little way toward alleviating the worries of restaurant owners $[5,6]$. Automating the process by which orders are taken and communicated to the kitchen reduces human error, making sure customers get their correct order and that accounts and payments are done accurately. POS systems also have the ability to increase managerial control so that managers can track all restaurant operations accurately. However, several investigations have shown that traditional POS systems are beginning to look inadequate in our current smart and connected business environment [7].

By opening traditional POS systems up to external developers as well as out towards the cloud, opportunities abound for restaurant owners to both simplify existing processes, such as coupon redemption, and execute wholly new initiatives, such as location-based marketing. The new startup industry of mobile POS (mPOS) systems enable $t$ lean functions to take into account restaurant-oriented design with an affordable price as well as a reasonable amount of time and effort. With mPOS systems, restaurants can gain benefits in their business environment. These systems provide better management tools for running the business of a restaurant. A decade ago, many IT companies tried to develop applications, hoping to make an appropriate process for supporting restaurants [8]. However, they often over pursuit system functions, while ignoring the requirements of what restaurants want; thus, the majority mPOS systems are unable to meet the goals of restaurants. The question remains, does IT matter?

Previous studies have shown a positive impact of IT on businesses, from helping firms enhance their operational efficiency to driving business growth and to integrate their marketing operations with marketing strategies $[9,10]$. However, IT has not always delivered business value. One of the key reasons is the lack of synergy between a firm's business strategy and IT strategy. IT strategic alignment studies have found positive effects of complementary business and IT strategy on business performance and the contrary among firms that have misaligned strategies [11-13]. While extant IT strategic alignment studies clearly demonstrate the importance of alignment and its performance impacts, the question is, how can businesses achieve alignment? The early 1990s were a period when researchers began to show that IT investments were not a magic bullet; rather, they required a radical change in the way in which an organization performs its business activities or changing operational process. Many authors have explored the relationship between IT and process change [14-16] as well 
as the role of IT and strategy $[17,18]$. The relationship between process and strategy has also been discussed in many studies [19,20]. However, there are few studies that discuss the impact of IT change on process change, and process change on strategy change. Moreover, the starting point of most of these studies is the changing of IT and process changes follow the changing of strategy. Therefore, the purpose of this study is to investigate the relationship among IT, process, and strategy.

The distinguishing point of this study is that we revisit the role of IT in process change and strategy change. Based on observations from the case of using mPOS in restaurants, we found that most organizations start to implement IT first, and then recognize the need to change processes to fully explore and exploit all the useful functions of IT. Over time, the whole organization is changed to another form that is different from the original form; thus, they start to think about new strategies for their business that relate to service and IT. What happens in this case completely fits the situated change perspective proposed by Orlikowski (1996) [21]. Therefore, this study aims to investigate the impact of POS change (from traditional POS to mPOS) on process change and strategy change based on situated change perspective. Situated change perspective believes that organizational change must be planned, that technology is the primary cause of technology-based organizational transformation, and radical changes always occur rapidly and discontinuously. More specifically, we examine the following questions:

- What is the impact of mPOS on the process change under situated perspective?

- What is the impact of process change on the changes of IT strategy and service strategy under situated perspective?

By collecting data from 10 restaurants in Taiwan, this study has aimed to develop a comprehensive model that describes the relationship among mPOS, process, and strategy. The results can enhance understanding on the role of POS change on process change and strategy change under the situated change perspective. The results also show that processes do not change only because of the use of technology. It is an ongoing improvisation enacted by organizational actors trying to make sense of and act coherently in the world. The results of this study can provide a typical model of these relationships, which may be beneficial for further studies. The remainder of the paper is organized as follows: the following section reviews theoretical background for developing framework and propositions, the next section describes data collection and analysis, and the last sections presents the results and the implications for researchers and practitioners.

\section{Theoretical Background and Proposition Development}

\subsection{Theoretical Background}

\subsubsection{The Strategic Alignment Model}

The concept of alignment originated from contingency approach studies about the alignment between the organization and the environment, and also from the systems thinking approach, allied to the concept of open systems [22].Strategic alignment between the business and IT is the process and goal of achieving competitive advantage through developing and sustaining a symbiotic relationship between business and IT [23]. The idea behind strategic alignment is very comprehensive, but the question 
is how organizations can achieve this ultimate goal. Figure 1 clearly describes the interrelationship between business strategies and IT strategies in the well-known Strategic alignment model.

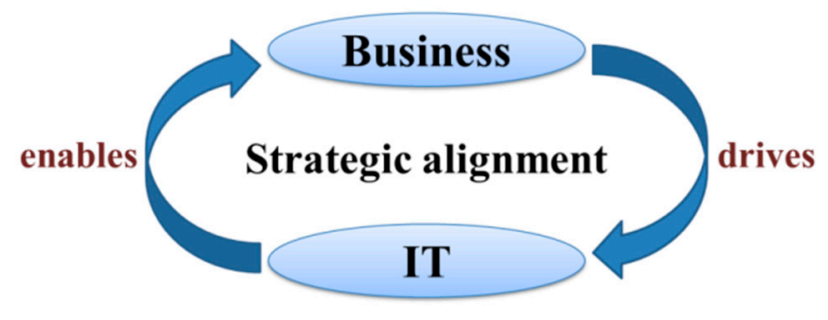

Figure 1. Business and IT strategic alignment.

The concept of the model is based on two building blocks: "strategic fit" and "functional integration" (Figure 2). Strategic fit recognizes that the IT strategy should be articulated in terms of an external domain (how the firm is positioned in the IT marketplace) and an internal domain (how the IT infrastructure should be configured and managed). Strategic fit is, of course, equally relevant in the business domain. Two types of functional integration exist: strategic and operational integration. Strategic integration is the link between business strategy and IT strategy reflecting the external components, which are important for many companies as IT emerged as a source of strategic advantage. Operational integration covers the internal domain and deals with the link between organizational infrastructure and processes and IT infrastructure and processes.

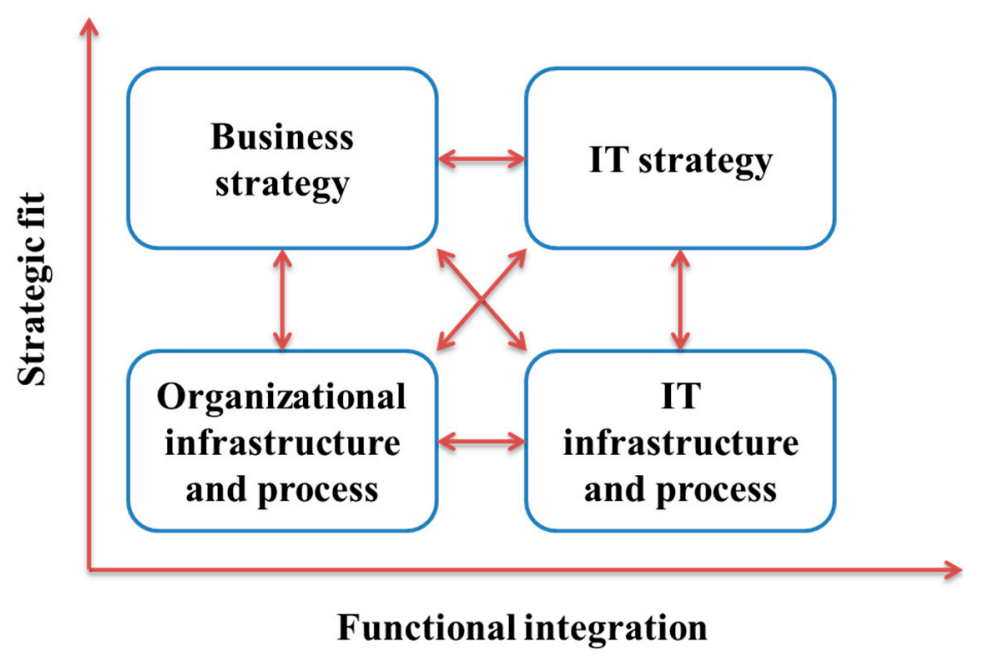

Figure 2. The "strategic fit" and "functional integration".

In this study, we focus on functional integration since we want to know how restaurants integrate mPOS into an organization and to link a company's IT strategy with its business strategy to obtain competitive and strategic advantage. We believe that a firm's development and use of technology can be managed so that it effectively supports the firm's business strategy. 


\subsubsection{Organizational Change under Situated Change Perspective}

The organizational change phenomenon has received many labels: radical change, strategic change, revolutionary change, strategic renewal, and organizational frame bending. Despite this diversity, the literature distinguishes two types of change: convergent change and deep structure change. Convergent change is a change process occurring within a relatively stable structure. An example of convergent change is an organization that improves its efficiency and effectiveness without rethinking its business model or key processes. The ambiguity stems from the fact that, from an evolutionist point of view, radical change is ultimately a series of incremental changes, whereas convergent change is always incremental.

Orlikowski (1996) outlines that stability is not the desired state of contemporary organization, since it has to be flexible and adjust itself to ongoing changes. Change is no longer a background but a way of organizational life. Organizational change in this case cannot always be planned or managed; it is seen as continuous process rather than predefined action with exact start and end milestones. A view of organizational changes situated change is grounded in assumptions of actions, not stability. Organizational change is seen as an ongoing improvisation enacted by organizational actors trying to make sense of and act coherently in the world. The focus of situated change perspective is on micro-level changes that actors enact over time. Seeing organizational change as situated, it suggests that change may not always be planned, inevitable, or discontinuous. Rather, it is understood through the ongoing variations, which emerge frequently, even imperceptibly, in the slippages and improvisation of everyday activity. Those variations that are repeated, shared, amplified, and sustained can, over time, produce perceptible and striking organizational change. These assumptions are highlighted in extensive empirical work, where unintended consequences can be characterized as positive (for instance sharing work experiences between graphically distributed offices) or negative (for instance manual development of paper based backup system). Therefore, situated change consists of the following characteristics: (1) changes cannot always be planned; (2) change is a continuous process; and (3) organizational change is the result of improvisations enacted by organizational actors and technology is not the main driver for organizational change.

\subsection{Proposition Development}

\subsubsection{The mPOS System and Process Change}

POS systems are often designed for a variety of clients, and can be programmed by the end users to suit their needs. The restaurant POS system interfaces with all phases of the restaurant operation and with everyone that is involved with the restaurant including guests, suppliers, employees, managers and owners. The selection of a restaurant POS system is a complex process that should be undertaken by the restaurant owner and not delegated to an employee. Recently, many restaurants start to use mPOS systems, which have become popular in the restaurant industry [24]. An mPOS is a smartphone, tablet or dedicated wireless device that performs the functions of a cash register or electronic point of sale terminal. mPOS implementations allow service and sales industries to conduct financial transactions in place, improving the customer experience (CX) and freeing up valuable real estate that would otherwise be dedicated to a POS countertop. An mPOS can also be cost-effective, allowing a small business owner to conduct transactions without having to invest in an electronic register or pay 
someone to support the software. Any smartphone or tablet can be transformed into an mPOS with a downloadable mobile app [25].

Processes are intrinsic to organization design. Academicians and practitioners alike have long used process concepts to distil and to elaborate characteristics of organization structure, work role behavior, and resource interdependence [26]. In organizational process research, Weick has argued that organizations construct processes from a set of "cycles" using "assembly rules" - in short, organizations build routines based on goal-directed rules and procedures, where rules are seen as constraints on action [27]. Other researchers have defined processes as coordination systems for managing resource dependencies in firms, using ideas from computer science and coordination theory to map process hierarchies and resource coordination [28]. Definitions of business processes have looked chiefly at the structure and specific ordering of work, using ideas from industrial engineering and, in some circumstances, from systems dynamics where the process focus crosses firm boundaries. Thus, Davenport defines business processes as the specific ordering of work activities across time and place, with a beginning, an end, and clearly identified inputs and outputs [15]. The process objective is customer value added: processes are the structure by which organizations do what is necessary to produce value for customers. Such definitions generally have implied process hierarchies.

By viewing mPOS as one type of information technology (IT), which is a commonly used term that changes meaning with context. From the first perspective, IT systems, applications and infrastructure are components or sub-assemblies of a larger product. They enable or are embedded in processes and services. From the second perspective, IT is an organization with its own set of capabilities and resources. IT organizations can be of various types, such as business functions, shared services units, and enterprise-level core units. From the third perspective, IT is a category of services utilized by business. These services are typically IT applications and infrastructure that are packaged and offered as services by internal IT organizations or external service providers. IT costs are treated as business expenses. From the fourth perspective, IT is a category of business assets that provide a stream of benefits for their owners, including but not limited to revenue, income and profit. IT costs are treated as investments. It is important to be clear what the term means in a given context. It is often used with different meanings in the same sentence or paragraph, often exacerbating problems. Based on the evidence from case study restaurants, we found that the use of MPOS can eliminate these unnecessary links in the three streams and the invalid steps in the process of value-added. Then, the enterprise can conduct process integration and optimization. Finally, the organization can make processes more agile and efficient.

Raschke (2007) points out that process agility consists of flexibility and employee adaptability [29]. According to Raschke (2007), flexibility refers to the ability to instantly change the order of activities within a business process. As has been noted, business processes are bundles of activities that may become quite complex. In such complex scenarios, individuals have to be able to modify the order of these activities. Flexibility may be mistaken as agility itself, though the sensing component is missing. Employee adaptability is defined as the employees' ability to adapt their working behaviors, as well as having an attitude to do so, if the environment is changing. Thus, employee adaptability may be left out for this contribution's confrontation.

Process efficiency means to review a process in order to streamline the process, increase process quality, and increase process effectiveness. The overall goal of increasing process efficiency is to 
lower costs and increase production. Efficient execution of the process is very important for very many reasons. First and foremost, every customer who is buying a service expects efficiency of service. Depending on the nature of the business or service, the process efficiency can be ascertained. Efficiency of service in a restaurant can be measured in terms of time taken from order to delivery of food. Process efficiency is not only important from the point of view of external customers alone. Internally too, process efficiency has a bearing on the operations cost as well. Internally, the process efficiency can be measured using several criteria, including total processing time, resource utilization per unit of output, cost of quality, and etc.

Therefore we propose Proposition 1: The changing of traditional POS system to mPOS creates more agile and efficient process in restaurants.

\subsubsection{Strategy Changes}

Strategy researchers have continued to debate both the sources of competitive advantage and firm performances (the "content" of strategy) and models of the strategic planning process (the "process" view). In firm performance, two contrasting perspectives are dominant: one looks to the importance of external market factors in predicting firm performance; the other looks to factors internal to the organization [26]. The external "industry forces" view derived much force from the work of Porter, who applied principles of industrial economics to strategy [30]. The dominant principle is that (industry) structure determines the conduct (strategy) of firms, and the collective conduct of firms then determines the overall performance of firms in the industry. Under these assumptions, strategy was concerned mainly with the placement of products in desirable market niches and defending those niches. A second perspective has been the resource-based view of the firm, which emphasizes unique combinations of resources that firms employ to obtain above-average rates of returns. Extensions of the resource view have shifted the focus from unique tangible resources as competitively advantageous, to a focus on intangible assets, such as knowledge, core competencies, or learning, as the primary source of advantage [26]. Other researchers hold that strategy formulation and implementation are not separable, that is "Thinking cannot be separated from doing". Here, the argument is that strategies emerge incrementally over time.

The main purpose of this study is the discussion the role of IT in changing process and strategy based on technological perspective and business perspective. We shift our focus on IT strategy and service strategy instead of general business strategy. IT strategy is a comprehensive plan that information technology management professionals use to guide their organizations. The service strategy provides guidance on how to design, develop, and implement service management not only as an organizational capability but also as a strategic asset. The service strategy is expected to be useful for organizations in developing capabilities in service management that set up and maintain a strategic advantage in their goals of being valuable service providers. An IT strategy has traditionally been expressed in a document that explains how technology should be utilized as part of an organization's overall corporate strategy and each business [31]. The Henderson and Venkatraman (1993) strategic alignment model (SAM) is the dominant model of IT and business alignment [32]. SAM defines strategy as choices involving both formulation (decisions pertaining to external competitive, product/market choices) and implementation (choices pertaining to the internal structures and 
capabilities of the firm in order to execute its product/market choices). Once processes are changed, the management needs to reformulate another strategy for business. They may figure out strategy for new IT as well as new strategy for providing services.

Therefore we propose Proposition 2: The agile and efficient process will lead to the changing of service strategy and IT strategy.

Based on the above discussion, we describe these relations in follow research framework (Figure 3).



Figure 3. Proposed research framework.

\section{Research Design and Methodology}

The concept of this study is different from previous ones. We intend to revisit traditional concepts about IT, process, and strategy to come up with a new model. The method used in the study will be "grounded theory", which stresses the "emergence" of theory derived directly from data rather than forcing the theory into predefined categories [33]. Grounded theory is developed in order to generate theory through the systematic and simultaneous process of data collection and analysis. The theory emphasizes the product of continuous interplay between analysis and data collection [33]. Knowledge is seen as actively constructed, with meanings of existence only relevant to an experiential world. Therefore, the focus of the qualitative study is to investigate the integration of MPOS on process and process on strategy. A multi-case study is useful in capturing the emergent and immanent properties of an instable context that is changing very quickly [34]. It is also more suitable in an exploratory analysis when the goal is to provide and answer to "how" questions, which aim to explain a certain phenomenon. This method enables gaining a holistic view of IT-Process-Strategy providing a rounded picture given the many sources of evidence used. 


\subsection{Case Selection}

\subsubsection{The mPOS System in this Study}

The mPOS system (hereafter is called iCHEF) is used in this study was developed by a famous restaurant in Taiwan to help improve its own service process. It was designed specifically to improve the restaurant's own operating process. Using the cloud computing system, iCHEF combines all the information needed by the restaurant. With iCHEF, restaurants can manage all the operations: monitor sales, guest count, and peak hour performance queuing, sending orders to kitchen, seating, serving, and printing out the receipt. What is more interesting, even if the internet is offline, iCHEF can still function normally. On top of that, iCHEF also supports the Taiwanese government's E-invoice standard, so restaurant owners can save time on filing government invoices as well as enjoy a tax benefit every year. The robust system allowed iCHEF to open up its solution to other restaurants. Soon after, approximately 100 restaurants signed on and are now paying for iCHEF's service. The number is currently still growing as more and more restaurants are signing up for the end-to-end solution. The main features of iCHEF are related to supporting operational processes: waiting line, table arranging, order, order handling, bill handling, payment, and document management.

\subsubsection{Restaurants}

We will conduct 10 case studies over one year to help us understand how restaurants define and manage alignment among mPOS, process, and business strategy. For using iCHEF, restaurants have to prepare equipment based on their sizes and features. The status of each restaurant is described in Table 1.

Table 1. Restaurants' features and iCHEF status.

\begin{tabular}{|c|c|c|c|c|c|c|c|c|c|}
\hline \multirow{3}{*}{ Features } & \multicolumn{5}{|c|}{ Western Style } & \multicolumn{4}{|c|}{ Eastern Style } \\
\hline & \multicolumn{3}{|c|}{ Café } & \multicolumn{2}{|c|}{ Set Meal } & \multicolumn{3}{|c|}{ Noodle } & \multirow{2}{*}{$\begin{array}{c}\text { Group } \\
\text { Dining }\end{array}$} \\
\hline & FR & $\mathbf{C A}$ & MAC & NO & GO & $\mathbf{C Y}$ & HA & MAZ & \\
\hline iCHEF & $\mathrm{Y}$ & $\mathrm{Y}$ & $\mathrm{Y}$ & Y & Y & Y & $\mathrm{Y}$ & $\mathrm{Y}$ & $\mathrm{Y}$ \\
\hline Equipment & $\begin{array}{c}1 \mathrm{iPad} \\
\text { 1Printer }\end{array}$ & $\begin{array}{c}1 \mathrm{iPad} \\
1 \text { Printer }\end{array}$ & $\begin{array}{c}3 \text { iPad } \\
2 \text { Printer }\end{array}$ & $\begin{array}{c}1 \mathrm{iPad} \\
\text { mini } \\
1 \mathrm{iPad} \\
2 \text { Printer }\end{array}$ & $\begin{array}{c}1 \mathrm{iPad} \\
\text { mini } \\
1 \mathrm{iPad} \\
2 \text { Printer }\end{array}$ & $\begin{array}{c}2 \mathrm{iPad} \\
\text { mini } \\
1 \mathrm{iPad} \\
3 \text { Printer }\end{array}$ & $\begin{array}{c}1 \mathrm{iPad} \text { mini } \\
1 \mathrm{iPad} \\
2 \text { Printer }\end{array}$ & $\begin{array}{c}2 \mathrm{iPad} \text { mini } \\
1 \mathrm{iPad} \\
2 \text { Printer }\end{array}$ & $\begin{array}{c}3 \mathrm{iPad} \text { mini } \\
1 \mathrm{iPad} \\
5 \text { Printer }\end{array}$ \\
\hline Size (seats) & 39 & 28 & 64 & 52 & 50 & 32 & 30 & 45 & 134 \\
\hline Floor & 2 & 2 & $\underline{2}$ & 1 & 1 & 1 & 1 & 1 & 1 \\
\hline Waiting area & $\mathrm{Y}$ & $\mathrm{N}$ & $\mathrm{Y}$ & $\mathrm{N}$ & $\mathrm{Y}$ & $\mathrm{Y}$ & $\mathrm{N}$ & $\mathrm{Y}$ & $\mathrm{Y}$ \\
\hline $\begin{array}{l}\text { Reservation } \\
\text { form }\end{array}$ & $\mathrm{N}$ & $\mathrm{N}$ & $\mathrm{Y}$ & Y & Y & $\mathrm{Y}$ & $\mathrm{N}$ & $\mathrm{Y}$ & Y \\
\hline \multirow{3}{*}{$\begin{array}{c}\text { Employees } \\
\text { (waiter/chef) }\end{array}$} & 6 & 6 & 10 & 8 & 7 & 7 & 3 & 10 & 17 \\
\hline & 2 out & 2 out & 4 out & 3 out & 2 out & 3 out & 2 out & 5 out & 7 out \\
\hline & 4 in & 4 in & 6 in & 5 in & 5 in & 4 in & $1 \mathrm{in}$ & 5 in & $10 \mathrm{in}$ \\
\hline
\end{tabular}


Among the 10 cases, we selected 9 representative cases to analyze because one restaurant uses a traditional POS system instead of mPOS. At the beginning, we conduct this case to have general view of traditional POS system. Each case has their own problems that need to be addressed and by leveraging the functions of mPOS, they fulfill their business strategy in different ways. The unit of analysis is an mPOS project that has a duration of at least 6 months. The restaurants are classified into 2 main groups based on their futures. Group 1 consist of Western style restaurants, and Group 2 are Eastern style ones (Figure 4).

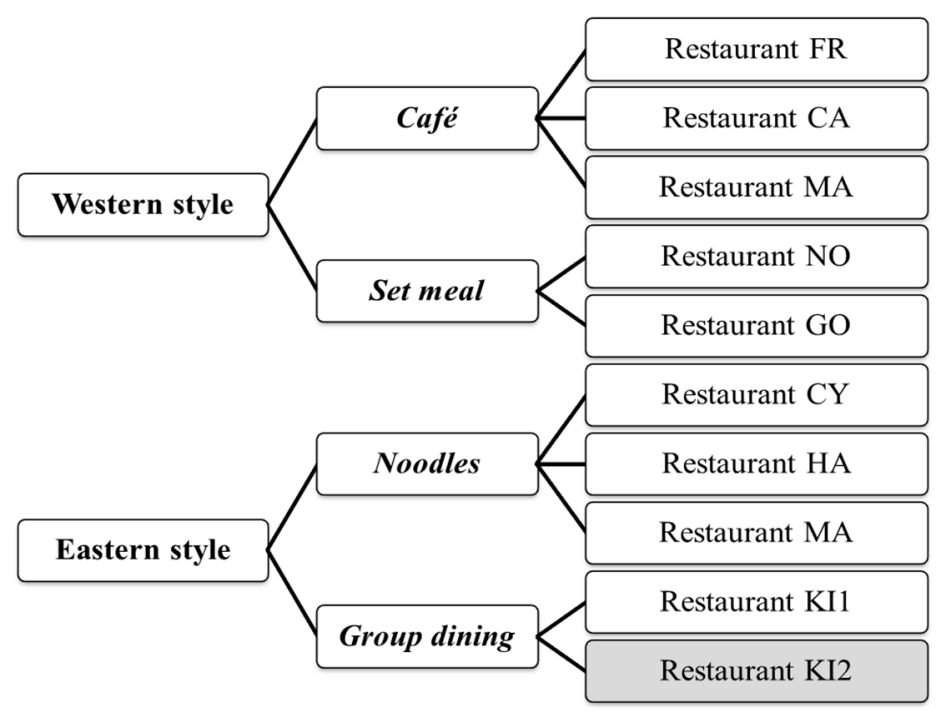

Figure 4. Restaurant classification.

\section{Restaurant FR}

Restaurant FR is a café, kitchen and gallery all in one, which is perfect for the traveller who wants some time away from the hustle and bustle of Taipei. The problem they are facing is that many cafés have the same style, and thus how can they enhance their competitive advantage, attract more customers, and deal with little investment capital. They want to create a new image for restaurant to let travelers feel more professional when they enter this restaurant. Without iCHEF, the restaurant also works well, they just need to build a professional image for customers. Because travellers aim to find something simple, yet professional in their journey, iCHEF is the best choice. In fact, this restaurant has not leveraged all functions of iCHEF system. According to the owner, she considered using iCHEF because it can work as a traditional system with lower costs. When applying iCHEF, all processes in the restaurant are kept as original status. The most important role of iCHEF is back-line service. The owner can collect daily information from the restaurant related to customers quickly from iCloud. This information helps her analyze the situation to make further decisions related to storage or menu changes. Therefore, the main role of iCHEF is improving activities.

\section{Restaurant CA}

Restaurant CA is the only café focusing on organic palm sugar in the world. After reforming this 50-year-old Taiwanese three-story building, Sugar Bistro created a vintage and modern atmosphere by maintaining the unique front yard, short wall and floor built by traditional Taiwanese architecture 
methods and arranging recycled objects and furniture with new ones. Sugar Bistro is delighted to offer hand-made light food and drinks that are uniquely made with organic palm sugar, and occasionally organize experimental events, lectures, and exhibitions. They need POS system to support their daily activities such as order and payment. They also do not want to spend too much for this system, thus iCHEF is the best choice because it is simple, cheap, and small. In other words, iCHEF functions meet the restaurant's needs. The main role of iCHEF is not different from a traditional system.

\section{Restaurant MAC}

Restaurant MAC is a French style restaurant located in a shopping area in Taipei. Customers would like to have drinks or lunch/dinner need to reserve in advance or wait for a long time since the food and beverage take time to prepare. In addition, due to the small size, they divide dining or serving areas into two floors, and it takes time for wait staff to deliver food/beverages to customers. The owner is trying to find a way to reduce serving time and calculate the exact response time for waiting customers, and so they have decided to implement iCHEF. Kitchen and bar are located on the first floor, and before iCHEF implementation, wait staff needed to bring an order from the second floor to the kitchen/bar. Now, by using iCHEF, after a customer finishes ordering, they can send the information to kitchen directly and the chefs have more time for preparation. The process to handle operational activities has become more flexible and efficient.

\section{Restaurant NO}

Restaurant NO is an American style restaurant that provides a full range of authentic New Orleans cuisine for customers prepared by a Taiwanese chef who has spent a long time to living in America. They face the same problem with Restaurant MAC. Located in Central Taipei, with a small area, customers need to reserve in advance or wait for long time. Later, they set a rule of two-hour maximum dining time for customers. However, by leveraging $\mathrm{iCHEF}$, they can calculate the dining time of each customer, and then inform customers the waiting time more exactly. This solution brings to customers a professional feeling when they come to NO. Moreover, although the owner is not always in the restaurant, he would like updated information daily. Based on cloud storage, he is able to get all information he wants promptly. To make sure that no mistakes happen or he can quickly find the reasons when mistakes happen, the manager requires all staffs to use the register function when using iCHEF.

\section{Restaurant GO}

With the purpose of providing customers a fresh feeling every morning, this restaurant creates a different environment of having a French style brunch area. The restaurant uses animals to mark the order of each customer. Western exchange students as part time wait staff give the restaurant its own style. Before using iCHEF, they already used iPads to handle ordering activities. However, iPads cannot support every operational activity. They considered using a traditional POS system. However, after consideration, they found that a traditional POS system is not suitable for a small restaurant like GO. Fortunately, iCHEF helps them to solve this problem by being small and flexible as well as having pictures to illustrate strange foods and beverages. 


\section{Restaurant CY}

Restaurant CY is a newly opened LA style Vietnamese pho and rice restaurant, seating about 25 people in a bright, new space with a row of tables leading up to a semi-open kitchen. Their goal is to bring new flair to traditional Vietnamese pho and bring a fresh image by providing myriad options for customers related to meats, noodles, spices, etc. However, when they present this information in a paper-based order form, customers feel it is too complicated to make a choice, leading to many mistakes and misunderstanding between customers and wait staff. This results in customers getting the wrong order. In some cases, wait staff take much time confirming customer orders. After iCHEF implementation, their main problems were solved. By analyzing different types of foods and classifying them into different categories, the restaurant and $\mathrm{iCHEF}$ cooperate to design a suitable paper-based menu and digital menu to make customer feel it is easy to make choices and it also helps wait staff avoid mistakes caused by customers misunderstanding their options. In a short time, wait staff can handle iCHEF's system well and thus enhance the performance of the restaurant.

\section{Restaurant HA}

Restaurant HA was founded in 1992, and is known as one of "the best traditional beef noodles" restaurants in Taiwan. After expanding the business, they are no longer able to work manually. They need supporting from IT, like a new POS system. However, with limited budget and competency to use IT systems, they are also unable to spend much money to get a traditional POS system; hence, iCHEF is also their best solution. Using iCHEF, they now apply orders in the advance function to help customer get their order right away when entering the restaurant. In addition, they have also learned how to process data to improve their understanding of the business status.

\section{Restaurant MAZ}

Restaurant MAZ is located in a busy shopping district, and they require both high quality food and service. In addition, due to the popularity of eating noodles, many customers come to store for both dining in and taking out. It is difficult for wait staff to follow customers' requirements because of the mixed ingredients in each bowl of noodles. They are also facing the same problems as Restaurant CY. Therefore, iCHEF is also one of best solutions for them. In addition, due to the popularity of noodles, to get competitive advantages, they must create something different from their competitors and the solution is to bring a professional feeling to customers. iCHEF supports them in fulfilling this goal.

\section{Restaurant KI1}

Restaurant KI1 is a chain restaurant that has several locations in Taipei and mainly specializes in Sichuan cuisine. The stylish, unfussy decor and tasteful lighting make this place feel like a special occasion, however, like the best Chinese restaurants, the air is filled with enthusiastic conversation. The problem this restaurant is facing is how to reduce serving time. Due to the large size with different eating areas (common and VIP rooms), the interaction between wait staff and customers and communication between wait staff and kitchen or bar take long time. In addition, receptionistis far from the kitchen and bar, the bar and kitchen are in different places, and operational processes are too 
complicated and take many steps, such as customers check menu at the entrance, get into restaurant, receive another menu, check food, order, get food and so on. Even when this restaurant was using a traditional POS system, the results did not meet their expectations. To enhance the performance, the owner decided to find a solution that can help them reduce operating time and so they chose iCHEF. This new system is integrated with the existing system and does not bring any changes in operational processes. They are willing to invest in another new system with the hope that they can bring more things to customers, not only good products and services. Since the other three restaurants in this chain still use a traditional POS system, which also works well, iCHEF is not really important for the enhancing performance of this restaurant, however, they want to follow the trend and invest in the future.

\subsection{Data Collection and Analysis}

The purposes of this study is to identify the impact of changing the POS system on process change and the influence of process change on strategy change. Thus, we select different methods to collect data. We intend to conduct qualitative research since the results of quantitative research may be unexpected or show different patterns. It is essential to get an in-depth understanding of the results. We gathered case-level data consistent with the logic and steps outlined in case study methodologies.

To fulfill the first purpose, we conduct a file study. By observing how all activities happen in the restaurants for one day, from the opening time to closing time, we can figure out the operational processes in the restaurants and the role of MPOS system in each activity. Observation is a method of collecting data without asking questions of respondents. People can be observed in their natural work environment or in a lab setting and their activities and behaviors or other items of interest can be noted or recorded. There are three to four people in our research team, based on the size of restaurants. Each member is responsible for observing one area. For example, we divide the restaurant into three main areas: reception, dinning/serving, and kitchen and/or bar. During the observation time, we also conduct time recording to measure the efficiency of each activity. This duty can be finished in either one day or two to three days depending on the quality of collected information.

For the second purpose, we will conduct interviews with the owners, managers, chefs, and wait staff before and after conducting the observation. The interview questions aim to identify the problems of the restaurants and to make them change strategy and choose iCHEF as well as the changes of processes and infrastructure before and after iCHEF implementation. We conducted lengthy, semi-structured interviews in each restaurant with three to five interviewees, the number depending on the size and complexity of the process in the restaurants. We decided to use the in-depth interview method to collect data since in-depth interviewing is a qualitative research technique that involves conducting intensive individual interviews with a small number of respondents to explore their perspectives on a particular idea or situation. The quality of the in-depth interview outcomes is sensitive to the experience and insight of the participants. Data will be collected through voicerecorded interviews and interview notes.

After observation, we start to draw the floor-map and process of each restaurant and figure out the differences between these restaurants from others that use traditional POS systems. For the data collected from interviews, the records will be turned into written transcripts. Methods of analyzing the 
data include full transcription of interviews, which are then analyzed line by line in order to identify every possible code. Theme analysis by extracting, categorizing and coding will be conducted afterwards. Qualitative content analysis will be adopted to identify themes as meaningful for analysis rather than physical linguistic units. The content analysis for this study will be conducted by open coding (relevant concepts will be categorized according to certain salient properties), axial coding (combines the data together in what seems significant to the understandings of the respondents) and selective coding (identify a core category as a vehicle for the integration of the other major categories thereby developing and refining theoretical claims).

For the reliability of data coding, in the coding process, the definition of each construct will be explained to the coders before they started the coding. All themes will be classified by three coders, including the researcher (Coder A) and two students, representing Coders B and C, respectively. These three coders are well trained in mPOS, process, and strategy. They are also capable of doing content analysis and data coding. The three coders will undertake the assessment of the themes and the categories and dimensions from the content of the interviews. In order to measure the reliability of the coding among the three coders, this study will adopt Holsti's (1969) reliability formula to check the reliability [35]. The chronological descriptions of the project's activities were constructed with respect to iCHEF process, describing how it came about, when it started, who was involved, the level of involvement, and the major outcomes. Through this work, an in-depth case history of the project was completed.

\section{Findings and Discussion}

\subsection{POS Change and Process Change}

Compared to a traditional POS system, the mPOS system has become more popular in the service industry, particularly in the restaurant sector. Unlike traditional POS, MPOS can operate simultaneously on different operating systems, such as Windows, Android, Apple, etc. The updated version of the system is automatically updated, without extra charge. A traditional hardwired POS system will incur an upfront (non-refundable) software license fee, an annual maintenance fee for upgrades, and possibly other charges for technical support and training. By comparison, the mPOS system will have minimal or no upfront fees, and low monthly fees. Monthly fees include instant upgrades to the technology, which are done remotely without any downtime or management costs to the business. This is a significant productivity advantage over traditional systems. The technology used for mPOS allows user to integrate a number of business and marketing functions into their POS system. For example, payments can be processed from anywhere within a business premises (not just at the front counter), and receipts can be sent directly to a customer's cell phone. In general, mPOS has advanced rapidly in recent years and offers small businesses a reliable, affordable, and flexible solution to their POS operations. The mains differences of these two systems are described in Table 2.

Before making the decision to use iCHEF, restaurants face some problems. iCHEF can be seen as a supporting tools in providing solutions. In order to get better results, restaurants try to figure out how to integrate the new system into existing processes, and one of the most common solutions is process 
change. Table 3 illustrates the existing processes and Figure 5 provides a new view of restaurant after implementing iCHEF.

Table 2. Traditional POS and mPOS.

\begin{tabular}{ccc}
\hline & Traditional & New \\
\hline Target merchant size & Medium to large & Small to medium \\
Pricing & Complex & Simple \\
Merchant account & Required & Included \\
Complexity & High & Low \\
Speed to market & Slow & Fast \\
Maintenance & Expensive & Cheap \\
Analytics & Available & Available \\
Aesthetics & Well & Slick
\end{tabular}

Business model IC fees and support-based IC fees and/or ad-based

Table 3. The existing processes.




Table 3. Cont.

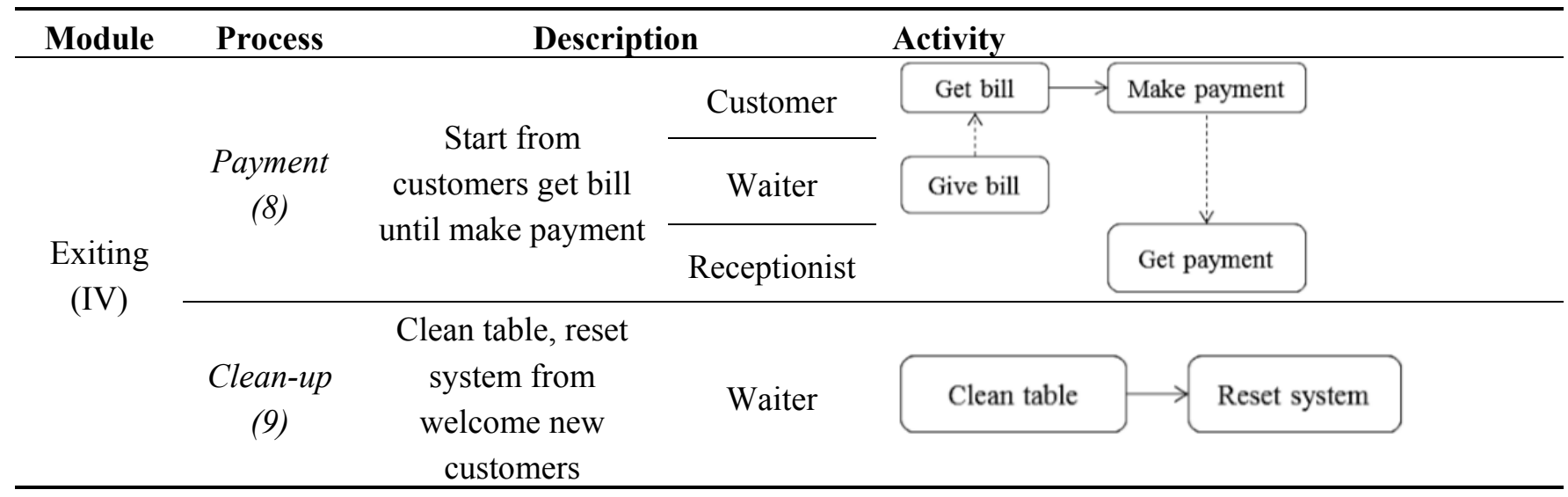

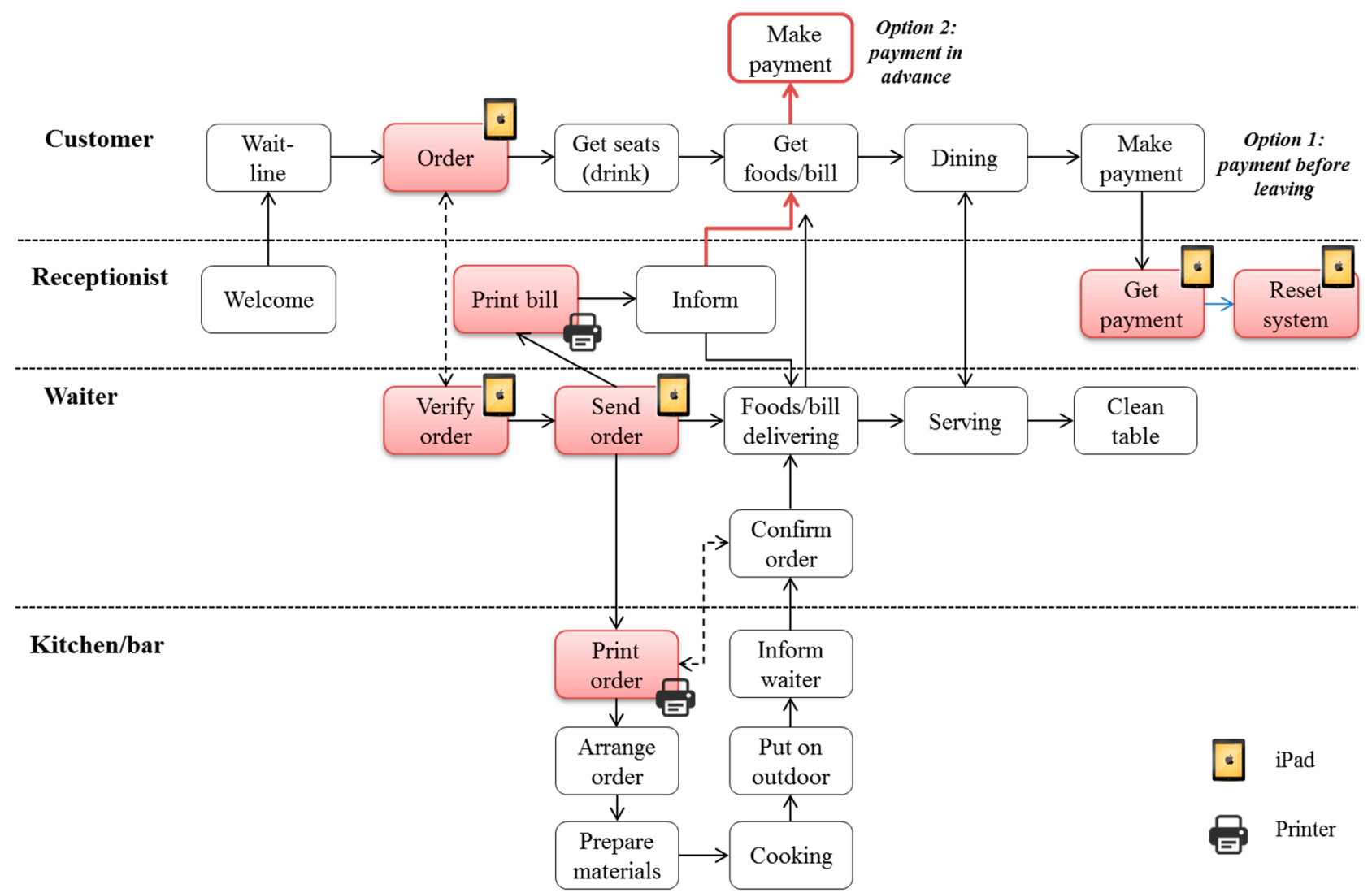

Figure 5. The new process.

At the beginning, operational activities in restaurants can be divided into four main modules and nine types of processes. Later, these activities are made shorter and can be classified into four main areas based on related stakeholders: customer, receptionist, waiter, and kitchen/bar.

After changing, the traditional processes become more efficient, agile, and professional. Related to agility, we focus on two dimensions: flexibility and employee adaptability. By using iCHEF, operational activities can be handled freely instead of in fixed order. For example, before customers should finish ordering, and then the wait staff input this information into the system, and finally send it to the kitchen. Now, while ordering, if customers do not want to wait for a long time, wait staff can send information to the kitchen in advance while continuing to take the order. In addition, by using iPad, 
which can be brought everywhere, wait staff can support customers anytime. Therefore, restaurants are able to get efficient productivity. The mPOS system not only supports restaurants staffs and managers, but also provides a fresh feeling to customers. This system eliminates mistakes related to ordering and making payment, thus customers feel more comfortable. The restaurants become more professional. In general, we can classify the benefits of iCHEF related to process improvement in to three main categories: efficiency, agility, and intangible value (Figure 6).

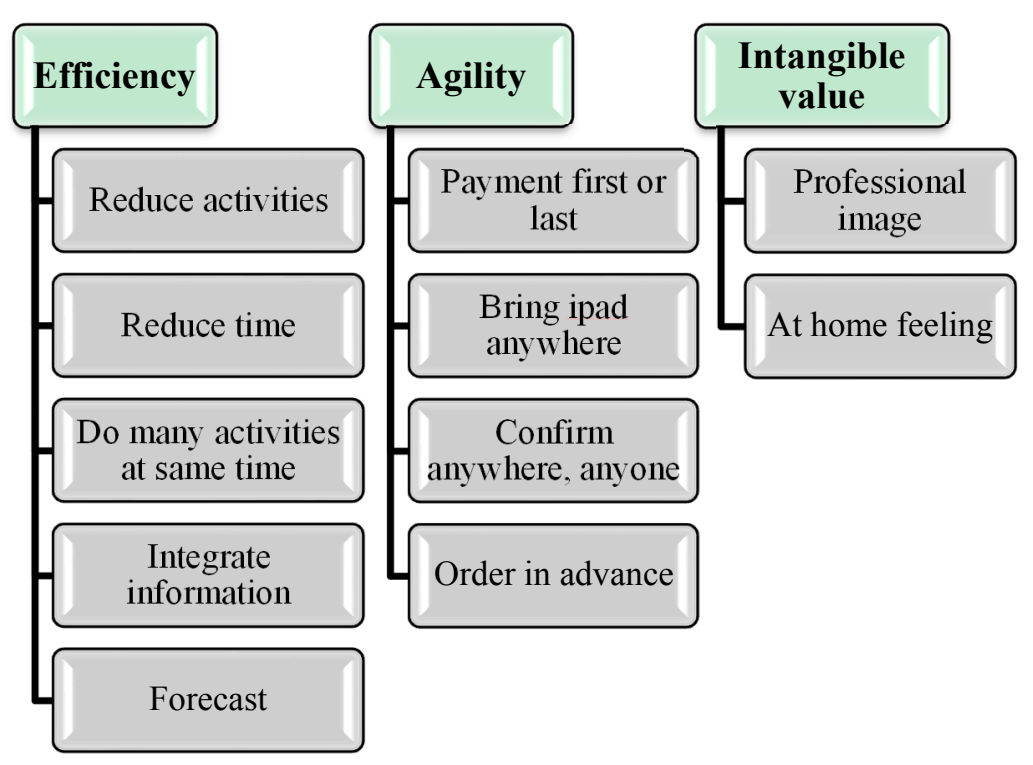

Figure 6. The benefits of iCHEF related to process improvement.

\subsection{Process Change and Strategy Change}

Once operational process is changed to become more agile, efficient, and professional, management can leverage this change to think about new things. They can conduct new strategies that were impossible to conduct before with traditional POS systems or without POS. IT must develop a means to engage the rest of the units of the company earlier so that they can play a role in shaping the plans of each of those units, and, after IT has a better understanding of what is necessary, an IT-specific strategy should be formulated. Facing the same situation, by leveraging iCHEF, managers should think about new strategies for their services.

Table 4 shows the main purposes of using the iCHEF system in nine restaurants. It looks like their focuses are different. They can also leverage other functions to provide more services to customers, or conduct more business plans. While using iCHEF, they can create different strategies to support services (Table 5).

Table 4. The purposes of using iCHEF.

\begin{tabular}{ccccccc}
\hline & $\begin{array}{c}\text { Complicated } \\
\text { Menu }\end{array}$ & $\begin{array}{c}\text { New/Strange } \\
\text { Food/Beverage }\end{array}$ & $\begin{array}{c}\text { Multiple } \\
\text { Serving Area }\end{array}$ & $\begin{array}{c}\text { Multiple } \\
\text { Cooking Area }\end{array}$ & $\begin{array}{c}\text { Small } \\
\text { Size }\end{array}$ & $\begin{array}{c}\text { Professional } \\
\text { Image Building }\end{array}$ \\
\hline FR & $\sqrt{ }$ & & & & & $\sqrt{ }$ \\
CA & & & $\sqrt{ }$ & $\sqrt{ }$ & \\
MAR & & & $\sqrt{ }$ & & \\
\hline
\end{tabular}


Table 4. Cont.

\begin{tabular}{|c|c|c|c|c|c|c|}
\hline & $\begin{array}{c}\text { Complicated } \\
\text { Menu }\end{array}$ & $\begin{array}{c}\text { New/Strange } \\
\text { Food/Beverage }\end{array}$ & $\begin{array}{c}\text { Multiple } \\
\text { Serving Area }\end{array}$ & $\begin{array}{c}\text { Multiple } \\
\text { Cooking Area }\end{array}$ & $\begin{array}{l}\text { Small } \\
\text { Size }\end{array}$ & $\begin{array}{c}\text { Professional Image } \\
\text { Building }\end{array}$ \\
\hline $\mathrm{NO}$ & & $\sqrt{ }$ & & $\sqrt{ }$ & & \\
\hline GO & & & & $\sqrt{ }$ & & $\sqrt{ }$ \\
\hline $\mathrm{CY}$ & $\sqrt{ }$ & & & $\sqrt{ }$ & & \\
\hline HA & & & & & $\sqrt{ }$ & \\
\hline MAZ & $\sqrt{ }$ & & & $\sqrt{ }$ & & $\sqrt{ }$ \\
\hline KI1 & & $\sqrt{ }$ & $\sqrt{ }$ & $\sqrt{ }$ & & \\
\hline
\end{tabular}

Table 5. Strategies description.

\begin{tabular}{ll}
\hline \multicolumn{1}{c}{ Strategy } & \multicolumn{1}{c}{ Description } \\
\hline Complicated menu & $\begin{array}{l}\text { Foods have many ingredients that customers need to select (type of } \\
\text { noodle, meat, source, spices, etc.) and sometimes they choose the wrong } \\
\text { thing as it is not clear, and thus difficult for chefs to cook. Restaurant } \\
\text { have many items to manage, not only food but extra items (gifts and } \\
\text { souvenirs) }\end{array}$ \\
\hline New/strange food/beverage & $\begin{array}{l}\text { Foods are from other countries and have strange names, which need } \\
\text { pictures to illustrate }\end{array}$ \\
\hline Multiple serving area & $\begin{array}{l}\text { Restaurants have many floors, many rooms, difficult to manage by } \\
\text { observation, need to use screen }\end{array}$ \\
\hline Multiple cooking area & $\begin{array}{l}\text { Restaurants have the bar and kitchen in different areas and so need to } \\
\text { receive order one time to save time, thus they should put printers in } \\
\text { different area }\end{array}$ \\
\hline Small size & Small restaurant with no place to put large machine \\
\hline Professional image building & Bring a professional feeling to customers \\
\hline
\end{tabular}

Moreover, restaurant can conduct new strategies if they are able to leverage all functions of this mPOS system. For example, iCHEF provide time calculating function, restaurants know the starting time, and finish time of each table. Based on this information, they can calculate the dining time of each customer. In the case that there are many customers waiting, the waiter/waitress can inform them of the expected waiting time so they know how long they will likely wait. At the same time, the kitchen also knows when they should start to prepare foods and beverage for waiting customers to keep the best quality of the foods. Another thing, by providing pictures on the screen, the restaurants can reduce the time it takes to introduce their menu to customers. For each type of dish, they can prepare some related pictures, if customers want to know about content, ingredients, or display of foods, wait staff can explain easily.

In addition, a subtler part of mPOS strategy is to build additional services into the mPOS offering. For example, mPOS can be designed to diffuse the checkout line, allowing people to check out their total purchases anywhere in the store, or purchase an item right on the shelf. The experience has been that the savings over traditional fixed checkout lines more than covers the increased attention to assuring all products get paid for. Moreover, the mPOS added value can be extended to the ordering process, as in a restaurant where orders are taken right on the payment device, eliminating the need for a separate step to generate a bill. Then, the payment can be processed using the same device. Giving 
the mPOS system the capability to capture consumers' phone numbers and email addresses during the transaction in a way that is easily downloadable directly to marketing databases represents another opportunity to add value.

\section{Conclusions}

In general, to maintain a competitive advantage, organizations need to consider how mPOS can add value to their business, both today and in the future. Many organizations recognize the benefits that mPOS can bring their businesses. Few, however, know how to go about realizing these gains. We can see that iCHEF has been targeting those restaurants that donot have their own IT department but focus heavily on improving their service quality. By using iCHEF, these independent restaurants can spend less time dealing with exhausting administrative and work. Being restaurant owners themselves, the iCHEF team always thinks and makes their decisions from their user's perspective. iCHEF takes this into consideration and focuses on providing a simple and easy to use solution that reduces the possibility of making mistakes. $\mathrm{iCHEF}$, as a vehicle to support business, translates their strategy into practice.

The findings of this study will provide a comprehensive view about the ways process change once organization implements different types of IT. In addition, we also figure out the impact of this change on IT strategy and service strategy. This study's results will shed a new light in IT implementation studies since the nature of IT are changing, researchers need to look IT in different ways and suggest suitable solutions for practitioners. We all understand that iCHEF or cloud-based POS systems will become more popular in the future along with the development of different types of tablets due to their advantages, such as being simple or low cost. To explore and exploit all the functions of this type of system, a restaurant needs to identify their strategy clearly and understand their restaurant's characteristics well because system implementation greatly depends on the restaurant's size, location, and cuisine. This study also opens another door for researchers in new POS system since cloud-based or tablet-based POS systems are different from traditional ones. Moreover, the findings also provide useful implications for restaurants that intend to leverage advantages of mPOS. They are able to figure out suitable strategiesfor IT investments to fit their business strategy. Through evaluation ofmature restaurants, owners can also identify which stage of IT investment they should focus on, factory, support, turnaround, or strategic.

\section{Acknowledgments}

The authors gratefully thank the mentioned restaurants for their detailed feedback.

\section{Author Contributions}

The authors contributed equally to this work. Yao Chin Lin (Y.C.L.), Nhu-Hang Ha (N.H.H.), and Kuo-Sung Lin (K.S.L.) jointly designed the research and prepared the manuscript. All authors have read and approved the final manuscript.

\section{Conflicts of Interest}

The authors declare no conflict of interest. 


\section{References}

1. Marcovic, S.; Raspor, S.; Segaric, K. Does Restaurant Performance Meet Customers' Expectations. An Assessment of Restaurant Service Quality Using a Modified Dineserv Approach. Tour. Horpitality Manag. 2010, 16, 181-195.

2. Venard, B. Organisational change in service multinationals: From radical change to destabilisation. Serv. Ind. J. 2002, 22, 57-76.

3. Kim, Y.G.; Eves, A.; Scarles, C. Building a model of local food consumption on trips and holidays: A grounded theory approach. Int. J. Hosp. Manag. 2009, 28, 423-431.

4. Gunasekaran, A.; Nath, B. The role of information technology in business process reengineering. Int. J. Prod. Econ. 1997, 50, 91-104.

5. Collins, G.R.; Cobanoglu, C. Hospitality Information Technology: Learning how to Use It; Kendall/Hunt Publishing: Dubuque, IA, USA, 2013.

6. Collins, G. Selecting POS systems for table service restaurants. Hosp. Rev. 1991, 9, Article 5.

7. Ng, T. "Echelon 2014: Run a restaurant? Let iChef take care of your orders" E27, 11 April 2014. Available online: http://e27.co/run-restaurant-let-ichef-take-care-orders-20150306/ (accessed on 23 September 2015).

8. Ching, J. iCHEF sets the new standard for restaurant POS system. Vulcan Post, 2014. Available online:http://vulcanpost.com/3579/taiwans-iCHEF-sets-the-new-standard-for-restaurant-pos-system/ (accessed on 23 September 2015).

9. Beheshti, H.M. The impact of IT on SMEs in the United States. Inf. Manag. Comput. Secur. 2004, $12,318-327$.

10. Roge, J.N.; Chakrabarty, S. Waiting for the other shoe to drop: Has information technology integrated marketing operations with marketing strategy? J. Comput. Inf. Syst. 2003, 43, 16-22.

11. Bergeron, F.; Raymond, L.; Rivard, S. Ideal patterns of strategic alignment and business performance. Inf. Manag. 2004, 41, 1003-1020.

12. Chan, Y.E.; Huff, S.L.; Barclay, D.W.; Copeland, D.G. Business strategic orientation, information strategic orientation, and strategic alignment. Inf. Syst. Res. 1997, 8, 125-150.

13. Tallon, P.P. A process-oriented perspective on the alignment of information technology and business strategy. J. Manag. Inf. Syst. 2008, 24, 227-268.

14. Attaran, M. Exploring the relationship between information technology and business process reengineering. Inf. Manag. 2004, 41, 585-596.

15. Davenport, T.H.; Short, J.E. The new industrial engineering: Information technology and business process redesign. In Operations Management: Critical Perspectives on Business and Management; Taylor \& Francis US: Florence, KY, USA, 2003; pp. 97-123.

16. Khan, T.H.; Khan, A.Q. Impact of Information Technology on BPR: A Study of Information Technology as BPR Enabler in Tractor Industry in Pakistan. J. Inf. Eng. Appl. 2014, 4, 49-59.

17. Erickson, T.J.; Magee, J.F.; Roussel, P.A.; Saad, K.N. Managing technology as a business strategy. MIT Sloan Manag. Rev. 1990, 31, Article 73.

18. Reich, B.; Benbasat, I. Chapter 10 Measuring the Information Systems-Business Strategy Relationship. In Strategic Information Management; Butterworth-Heinemann: Waltham, MA, USA, 2013; p. 265. 
19. Kettinger, W.J.; Teng, J.T. Aligning BPR to strategy: A framework for analysis. Long Range Plan. 1998, 31, 93-107.

20. Rathnam, R.; Johnsen, J.; Wen, H.J. Alignment of business strategy and IT strategy: A case study of a fortune 50 financial services company. J. Comput. Inf. Syst. 2004, 45, 1-8.

21. Orlikowski, W.J. Improvising organizational transformation over time: A situated change perspective. Inf. Syst. Res. 1996, 7, 63-92.

22. Prieto, V.C.; de Carvalho, M.M. Strategic alignment and performance: Brazilian companies in the medical diagnostics sector. Serv. Ind. J. 2011, 31, 1405-1427.

23. Van Grembergen, W.; de Haes, S. Enterprise Governance of Information Technology: Achieving Strategic Alignment and Value; Springer: New York, NY, USA, 2009.

24. Moon, Y.J.; Kim, W.; Ham, S. Users' intentions to employ a Point-Of-Sale system. Serv. Ind. J. 2014, 34, 901-921.

25. Park, M. Poisoned POS-A Case Study in iOS Based Mobile Point-of-Sale Gone Wrong. Available online: https://owasp.confex.com/owasp/appsecusa13/webprogram/Session1206.html (accessed on 23 September 2015).

26. Earl, M.J.; Sampler, J.L.; Short, J.E. Strategies for business process reengineering: Evidence from field studies. J. Manag. Inf. Syst. 1995, 12, 31-56.

27. Weick, K.E. The Social Psychology of Organizing (Topics in Social Psychology Series); McGraw-Hill: New York, NY, USA, 1979.

28. Malone, T.W.; Crowston, K. The interdisciplinary study of coordination. ACM Comput. Surv. (CSUR) 1994, 26, 87-119.

29. Raschke, R.L. An Empirical Analysis of Business Process Agility: Examining the Relationship of IT on Business Process Agility and the Effects of Business Process Agility on Process Outcomes; Arizona State University: Tempe, AZ, USA, 2007.

30. Porter, M.E. Competitive Strategy: Techniques for Analyzing Industries and Competitors; Simon and Schuster: New York, NY, USA, 2008.

31. Dubey, S.S.IT Strategy and Management; PHI Learning Pvt. Ltd.: Delhi, India, 2010.

32. Henderson, J.C.; Venkatraman, N. Strategic alignment: Leveraging information technology for transforming organizations. IBM Syst. J. 1993, 32, 4-16.

33. Stern, P.N. Eroding grounded theory. In Critical Issues in Qualitative Research Methods; SAGE: Thousand Oaks, CA, USA, 1994; pp. 212-223.

34. McCutcheon, D.M.; Meredith, J.R. Conducting case study research in operations management. J. Oper. Manag. 1993, 11, 239-256.

35. Holsti, O.R. Content Analysis for the Social Sciences and Humanities; Addison-Wesley: Boston, MA, USA, 1969.

(C) 2015 by the authors; licensee MDPI, Basel, Switzerland. This article is an open access article distributed under the terms and conditions of the Creative Commons Attribution license (http://creativecommons.org/licenses/by/4.0/). 